\title{
Leading Teams of Higher Education Administrators: Integrating Goal Setting, Team Role, and Team Life Cycle Theories
}

\author{
Richard Posthuma ${ }^{1} \&$ Said Al-Riyami ${ }^{1}$ \\ ${ }^{1}$ University of Texas at El Paso, USA \\ Correspondence: Richard Posthuma, University of Texas at El Paso, USA. E-mail: rposthuma@utep.edu
}

Received: June 29, 2012 Accepted: July 9, 2012 Online Published: August 22, 2012

doi:10.5539/hes.v2n3p44 URL: http://dx.doi.org/10.5539/hes.v2n3p44

\begin{abstract}
Leaders of higher education institutions can create top management teams of academic administrators to guide and improve their organizations. This study illustrates how the leadership of top management teams can be accomplished successfully through a combination of goal setting (Doran, 1981; Locke \& Latham, 1990), understanding of team roles (Belbin, 1999), and managing team life cycles (Tuckman, 1965; Tuckman \& Jensen, 1977). Using team goals, roles, and lifecycles, a model of higher education top management team leadership is derived. That model is compared to an actual case in which these concepts were successfully used to lead a group of academic administrators to the successful conclusion of jointly drafting a report that describes improvements in student academic and career advising.
\end{abstract}

Keywords: academic administration, teams, leadership

\section{Introduction}

Many scholars have recognized the lack of sufficient numbers of leaders and the need for more effective leadership in higher education institutions (Alfieri, 2009; Grubb \& Flessa, 2006; Kezar, Carducci, \& Contreras-McGavin, 2006). Effective leaders are needed in higher education in order to successfully plan for the future, change and reform their institutions, adapt to global competition and technological changes, and maintain sustainability, and update curricula (Alfieri, 2009; Aloi, 2005; Bland, Starnaman, Henbroff, Perlsatadt, Henry, \& Richards, 1999; Browne, 2005; Gioia \& Thomas, 1996; Mihel, 2010; Miller \& Molina-Ray, 2010). Several solutions have been proposed to address the need for more leaders including organizational development interventions (Keenan \& Marchel, 2007) and leadership development programs (Hornyak \& Page, 2004).

In addition, prior research has also recognized the need for more collaborative efforts in higher education (Brown, Benson, Walker, Sternberger, Lung, \& Kassinove, 2004; Giles \& Yates, 2011; Maguad, 2011). One way to promote collaboration in higher education is to distribute leadership across diverse groups and multiple individuals (American Society of Higher Education, 2007; Fincher, Katsinas \& Bush, 2009; Grubb \& Flessa, 2006; van Ameijde, Jitse, Nelson, Billsberry \& van Meurs, 2009). Distributed leadership can be enhanced through the creation of collective groups that function as effective leadership teams (Eddy \& Murphy, 1997; Rowley, 1997; Wageman, Nunes, Burruss, \& Hackman, 2008). In fact, there is growing evidence from many countries that higher education institutions are using teams in higher education administration (Chipunza \& Gwarinda, 2010 (South Africa); Hamdy \& Anderson, 2006 Saudi Arabia, United Arab Emirates, Kuwait, Oman, Qatar, and Bahrain); White, Carvalho, \& Riordan, 2011 (Australia, South Africa, Portugal); Woodfield \& Kennie, 2008 (United Kingdom); Smrekar \& McGraner, 2009 (USA).

However, very little is known about how groups of academic administrators can and do work together in teams (Woodfield \& Kennie, 2008). Little is known about how teams can achieve the goals of their institutions (Hirschy, 2011). Moreover, there is a concern and skepticism that higher education institutions are so different from other organizations that managerial team processes that are effective in other organizations might not work well in universities (Kekale, 1999; Serrano-Velarde, 2010; Woodfield \& Kennie, 2008). For these reasons, there is a critical need to understand how teams function in the administration of institutions of higher education and to determine whether or not teams can function well in this setting.

Therefore, this study was undertaken in order to study the effectiveness of leadership of top management teams in higher education institutions. It is hoped that this study will initiate the publication of a series of other 
comparable studies that will also examine the effectiveness of teams in higher education in many different countries and cultures in order to enable the sharing of information about successful techniques and best practices (Barth, 2004).

\section{Theoretical Background}

This study draws on three topics: team goal setting, team life cycles, and team member roles. There are extensive research literatures on each of these three topics. However, we integrate those three topics into a single model of effective team functioning.

\subsection{Goal Setting}

Goal setting is the process whereby targets and objectives are established. Research has shown that when certain types of goals are set, then the levels of performance tend to be higher. In addition, prior research has recognized goal setting as an essential part of university administration (Patterson, 2001). Yet, because of the complexities and politics of university environments, goal setting models need to be adapted and modified to make them applicable to the university setting (Patterson, 2001).

Nevertheless, one of the most consistent findings in the goal setting literature is that specific and challenging goals are helpful in focusing attention and achieving higher levels of performance (Locke \& Latham, 1990). These goals act as a unifier of potentially conflicting opinions thereby helping teams to coalesce their efforts to focus on achieving the goal. The research literature recommends that goals should include five characteristics. Goals should be specific, measurable, achievable, relevant, and time bound (SMART) (Doran, 1981). Thus, goals should be specific and not vague. Goals should be measurable through some quantitative or numerical scale. They should be achievable meaning that they are challenging, yet feasible. Goals should have time limits when the measurement of goal achievement is assessed. Using these definitions our model proposes that SMART goals will help teams of academic administrators achieve better results.

\subsection{Team Roles}

Effective teams include a diverse set of team members. Prior research has emphasized the importance of demographic diversity in higher education (American Society on Higher Education, 2007). However, another type of diversity that can help teams to be more effective is the diversity of team member's social roles. Social roles are expected sets of behaviors and patterns of social interactions that set boundaries on how people interact with each other.

Prior research has shown that individuals who work in effective teams tend to adopt differing social roles (Belbin, 1999). That line research of research has identified 8 common team member roles: Completer-Finisher, Implementer, Team Worker, Specialist, Monitor Evaluator, Coordinator, Plant, Shaper, and Resource Investigator (Belbin, 1999; van Dierendonk \& Groen, 2010). Research across many organizations and governmental entities confirms that people often classify themselves into these team roles (Aritzeta, Swailes, \& Senior, 2007). Effective team leaders are aware of the different roles that their individual team members have adopted and the use this awareness to lead the team (Clawson, 2006).

\subsection{Team Life Cycles}

Research confirms that teams tend to proceed through stages (Tuckman, 1965; Tuckman \& Jensen, 1977). Because of this, team leaders are more successful when they understand the nature of team stage changes (Gersick, 1989). During the forming stage the team members spend time getting to know each other and beginning to decide how they will work together as a team. During the storming stage, it is common that team members encounter differences of opinions about how the team should function, and this can lead to conflicts within the team. During the norming stage, the team members work together to resolve their conflicts and establish formal or informal social rules about how they will operate. During the performing stage, the team members work together and make progress toward accomplishing the goals of the team. During the adjourning stage, the team works through the process of disbanding.

Team leaders need to be aware of the developmental stage of their teams so that they can choose interventions that will be most effective, given the stage of the team (Wageman, Fisher, \& Hackman, 2009). For example if a team is still in the initial stage trying to get to know each other, it may be too early and counterproductive to force the team to focus on specific solutions for achieving their goal. If forced to do so, the team might not spend the time necessary to develop effective social relationships essential to team functioning. Thus, team leaders need to monitor the stages teams in higher education so that they can decide what intervention to use at any given point in time. 


\section{Integrating Goals, Roles, and Stages in Higher Education Teams}

We expect that none of these three models, standing alone, is sufficient to explain how people behave in teams. Therefore, we integrated these three theoretical perspectives into a single model. That model is illustrated in Figure 1. We placed an arrow in the center of the figure to represent the centrality of specific, measurable, achievable, relevant, and time bound goals. Goals that meet these criteria are much more likely to enable teams to achieve higher levels of performance. The figure includes four sections in an oval that represent examples of the different team member roles. Recognizing that individuals within teams can take on different roles, is important to understanding how teams function. The arrow in the center represents the stages of the team development. Reading these stages from left to right, the terms represent the different stages that teams typically pass through as they work toward achieving their goals.

\subsection{Goal Setting of Teams in Higher Education}

When the stated goals of teams in higher education settings meet the SMART criteria, they are specific, measurable, achievable, relevant, and time bound. We describe each of these concepts more completely and give examples for higher education settings below.

Specific means that the goal has sufficient detail that it can be clearly understood what it is that the team is trying to accomplish. A goal that would simply say, "We will do our best" is vague and not specific. A goal that states, "We will increase graduation rates by $5 \%$ by 2014 " is specific. Specific goals are better than vague goals. Specific goals are more likely to result in higher team performance.

Measurable means that the goals are stated in such a way that they can be assessed to determine the extent to which they have been achieved. Typically such assessment entails the use of numerical data, statistics, etc. If goals are stated in a way that would make it nearly impossible to determine the extent to which they have been achieved, then they are not measurable. For example, a goal that states, "We will reduce the average time to graduation by 2 weeks" is measurable. However, a goal that states, "We will work toward improving educational experiences" would be difficult to measure. Measurable goals are better than unmeasurable goals. Measurable goals are more likely to result in higher team performance.

Achievable means that goals are stated in such a way that if the team exerts directed effort it should be able to accomplish the goal. Goals that are achievable can motivate teams toward goal achievement because the team can visualize how their efforts can facilitate meeting the goal. Goals that are set too high are not achievable. Non-achievable goals will not motivate teams because they will quickly realize that working toward such goals will be a frustrating waste of their time and efforts. For example, a goal that states, "We will increase admission test scores by $10 \%$ by next year" could be achievable and therefore motivate the team. However, a goal that states, "We will have the highest graduation rates in the country" could be too high and therefore will not motivate the team because they could not see how it could be accomplished. Achievable goals are better than unachievable goals. Achievable goals are more likely to result in higher team performance.

Relevant means that the goal has important meaning within the context in which the team operates. Relevant goals are consistent with what people are supposed to be doing as a team. Relevant goals can be tied to the mission and strategies of the particular university, college, or department. Irrelevant goals are not related to the purpose the team. For example, a goal that states, "We will increase job placement rates of students by $10 \%$ " is relevant. A goal that states, "We will increase our participation in community organizations" may not be as relevant to the purpose of the team. Relevant goals are better than irrelevant goals. Relevant goals are more likely to result in higher team performance.

Time-bound means that goals must be accomplished by a specific time or date. By making the goal time bound, it will be possible for teams to know when they should focus their energies toward accomplishing the goal. Goals that are not time bound enable teams to get distracted by other priorities and not work toward achieving the goal. A goal that states, "By the end of the next academic year, we will increase the number of faculty peer-reviewed publications by $10 \%$ " is time-bound. A goal that states, "We need to improve the quality of our research productivity" is not time-bound. Time-bound goals are better than goals that are not time bound. Time-bound goals are more likely to result in higher team performance.

When leading teams in higher education it will be important to use SMART goals. Thus, teams should be encourage to adopt goals that meet the SMART criteria. If teams are either not adopting goals, or the goals that they adopt do not meet the SMART criteria, then the person leading the team should intervene to redirect the team's efforts toward the establishment of and engaging in targeted efforts toward attaining SMART goals.

Goals that meet the SMART criteria are more likely to result in higher performance. However, goals alone will 
not achieve the optimal level of performance. The effectiveness of these goals will be enhanced when they are used in a context in which teams understand the different roles that team members play, and also the stages of the life cycle of teams. Thus, when all of the members of the team focus on the same SMART goal, the team will be more likely to accomplish that goal.

\subsection{Understanding Team Roles in Higher Education}

When people become members of a team, they often have several different roles. In higher education settings the members of the team could have formal roles such as students, faculty, and administrators. Each of them may have their own job title which helps to define their formal role. However, in addition to these formal roles, people usually also adopt more informal roles. They will often adopt these informal roles based on personal dispositional or situational factors. Examples of the informal roles that people play in teams are illustrated in Figure 1. The four role titles used in this figure examples of the many different types of informal roles that individuals adopt while they work in teams (Belbin, 1999).

The coordinator is a team member who is person-orientated and exercises leadership to keep people working together. In this way the divergent efforts of multiple team members can meld together to achieve a higher level of team functioning. For example, the coordinator could notice that a lot of helpful ideas are emerging from the team discussions, but no one is taking notes. Thus, the ideas may be lost or forgotten before future meetings. The coordinator could suggest that someone take on the role of both recording the main points of the team discussion and then distributing them to other team members after the meeting.

The team worker is someone who intervenes in the team processes using their diplomatic skills to maintain team spirit and facilitate contribution by all team members. The person who adopts this role will facilitate the social processes and interactions amongst team members. For example, suppose that a team in higher education settings includes faculty members of different rank, some with tenure and some without. The team worker could notice that the junior untenured faculty may not be willing to speak out and offer their opinions, even though those opinions are important to the overall successful functioning of the team. The team worker could intervene encouraging the junior faculty members to speak up, perhaps by getting the senior faculty members to state that the junior faculty members should feel free to speak their minds without fear of retribution.

The resource investigator is a team member who seeks out new information about resources that the team can use to accomplish its goals. The person in this role can help the team to function better by obtaining the things that the team needs. In higher education settings, the resource investigator might be the person responsible for finding a place for the team to meet, for obtaining data or reports that the team needs, or for gaining access to online information sharing resources for the team, etc.

The completer-finisher is someone that uses steady effort to complete tasks thoroughly so that the team accomplishes its goal. The person adopting this role will help the team to stay on track and not get distracted by topics unrelated to the team goal. In higher education settings there could be mixed teams of academic administrators and faculty members. It is possible that academic administrators might be more adept at playing the role of completer-finisher since they may typically function in an environment where shorter time horizons for project completion are expected. By contrast, faculty may be more adept and understanding the complexities of problems and challenges and therefore more adept at playing a different role.

When leaders and team members understand the informal roles that they themselves and others within their team have adopted, they can better adapt to each other to achieve a higher level of team performance. Thus, in order to help the team function better, team leaders should teach the team members about the roles that different members of the team will play and encourage them to work together using these roles. For example, the leader of a higher education team could notice that one of the members of the team is emerging as the coordinator. Then, the team leader could encourage that person to continue to play the role in order to help the team to function better. The team leader could also explain to other team members that this person has been designated as the coordinator. Similarly, the team leader sees how other members of the team are adept at other roles, the people playing those roles can be encouraged as well.

Moreover, a critical insight of the model presented in Figure 1 is that the roles team members play and the goals that they set can be intertwined into a complex model of successful team functioning. Thus, SMART goals can produce better results. A better understanding of team roles can help the team to function better and achieve higher results. But goals and roles can work together synergistically to produce an even higher level of team functioning. This can occur when the team leader understands how to direct team member roles toward the SMART goals that the team has established. 
Thus, the team leader should not just enhance team member understanding of their roles, but direct their role activities toward the specific SMART goal that the team has established. For example, when interacting with the team member who has adopted the role of coordinator, the team leader can encourage that person to coordinate the team in a way that is directed toward the SMART goal. The team leader might say, "Let's keep in mind that the overall goal is to increase graduation rates by $10 \%$, please help to coordinate the team's efforts toward that specific goal." Similarly, when interacting with a team member who as adopted the role of resource investigator, the leader can encourage that person to seek out resources for the team, but not just any resources. That person can be encouraged to seek out resources that will facilitate the achievement of the that particular SMART goal. The team leader can engage in similar interactions with others in the team based on whatever roles they have adopted. In each case, the efforts of the leadership are not just directed toward enhancing effective role functioning, but at directing role functioning toward the SMART goal.

\subsection{Team Life Cycles in Higher Education}

Teams in higher education settings are likely to pass through a cycle of stages called forming, storming, norming, performing, and adjourning. In general, these stages occur in a chronological sequence, from the initial formation of the team to eventual adjournment. However, teams also move back and forward among these different stages as well. We describe each of these stages more completely and give examples for higher education settings below.

At the forming stage team members begin to transition from being individuals, to accepting and understanding their role as team members. Initially, there may be a great deal of uncertainty about how the team will function and team members may be likely to be highly attentive to information at this stage as they seek to gain understanding of how they will operate. In higher education settings, the forming stage may be dominated by people with stronger personalities or with higher ranking formal roles and job titles. The team leader can facilitate effective functioning of the team by setting clear direction and encouraging all team members to participate regardless of their position in the university.

At the storming stage team members encounter differences of opinions and conflicts about how the team will function, team roles, strategies and tactics. Storming is common, but can be worked through effectively. In higher education settings, it may be common for tenured faculty to speak their mind and this may exacerbate conflict. Also, persons from different academic backgrounds and disciplines may have significant differences in their perspectives and points of view. The team leader can facilitate effective functioning by active listening and successfully working to integrate the diverse perspectives that different people bring to the team.

At the norming stage team members find ways to resolve their differences and establish formal or informal social rules, called norms, that establish how the team will function. In this way the team members can reconcile their own points of view to the team by following team norms. In higher education settings, norms may tend to follow patterns of social interaction that reflect other social norms in the particular university or in higher education in general. While the team is establishing its norms, one of the most effective roles that the leader can play is to listen and advise, rather than direct the team. In this way the team members will be more likely to accept the norms that they establish for themselves.

At the performing stage the team uses the social norms that it has established in order to accomplish the task at hand. Performing entails achieving the goal that the team has established. In higher education settings, there may be a reluctance by some faculty members to a actively and energetically participate in activity that may be deemed less important. For example, if the faculty feel that their participation is part of their service obligation it may not be viewed as important as other activities such as research and teaching. By contrast, academic administrators may have a different point of view. They may be less likely to actively participate in the team performance if they view their participation as conflicting with other work roles that they need to fulfill. Thus, the team leader may need to support the team at this stage by reviewing performance and continuing to provide motivation by emphasizing the importance of the team goal.

At the adjourning stage the team has successfully completed its work and disbands. This stage is important because too often teams tend to take on a life of their own and can engage people in unproductive activities that are not linked to the mission of the university. At this stage, the leader can facilitate successful adjournment by providing team members with recognition and rewards for their performance. For example, in higher education settings, certificates, awards, letters, etc. can be used provide this recognition. Often these are appreciated in situations where team members will be asked to document their work performance at some future date.

An important insight of this article is that a better understanding of team life cycle stages can facilitate more effective functioning of teams in higher education. However, even more so, this article points out that there is an 
important relationship between team stages and team goals. Both stages and goals need to be managed synergistically in order to facilitate higher team functioning. Thus, in higher education settings team leaders need to help the team to establish SMART goals during the early stages of the team and to help them to maintain their focus on the SMART goals through the life cycle of the team. In this way the team leader can help the team to avoid what has been called, "mission creep" which is a process whereby the mission or objective tends to creep or move into additional areas.

Another important insight of this article is that thorough a better understanding of how to manage the stages in the life cycle of higher education teams, they can function more effectively. However, Figure 1 shows that these team life cycles operate within a context in which different members of the team take on different roles. Thus, it is not just that the effective leadership of different stages is important. In addition, the effective leadership of different roles at different stages is also important. In fact team members may change their roles at different stages of the life cycle of the team. An effective team leader may even want to encourage this.

For example in higher education settings, someone who is on the team and during the formation stage was acting as the coordinator, may be later tasked to be the resource investigator because someone else on the team has left the university. The leader of teams in higher education may also need to be sensitive to external and contextual factors that may induce the need for a change in team member roles at different stages. Thus, for example, when a deadline for submitting accreditation reports is approaching, the leader may need to induce more members of the team to take on roles that are akin to the completer-finisher role. These examples illustrate that effective leadership of teams in higher education settings needs to take into account both the stage of the team and also the dynamic roles that team members play.

\section{Application of the Integrated Model}

Consistent with the call for more case studies on best practices in higher education institutions (Barth, 2004), the integrated described herein was used to guide a team of academic administrators at a major university in the U.S. That team was charged with writing a report that summarized the improvements in student academic and career advising. The report was required by an agency that accredits the university. Consistent with prior research in higher education the names of the institution and individuals on the team have been kept anonymous (Aloi, 2005).

To complete this project, the team leader set a goal that met the SMART criteria and distributed that goal to all team members. In addition, the team leader prepared monthly status reports that included the goal. An example of one of the status reports is included in Figure 2.

Figure 2 is a status report that indicates the current state of the team development during one of the stages of the team's life cycle. Recognizing and recording the state of the team process and functioning team on the status reports enabled the team leader to recognize the need for and make appropriate interventions at each stage of the project, and also to communicate these to the team members. In addition, the status report identifies the four sub-goals that were required to complete the main goal. Each sub-goal had specific target dates for completion. A timeline was created to track the completion of each of the sub-goals. The goal date and percentage completion were updated on a monthly basis so that the team members could see progress toward achieving the overall goal.

In addition, the status reports identified the roles that had been adopted by each member. This enabled the team leader and members to better understand their own roles and the roles of other team members. This enhanced understanding reduced ambiguity and enabled better understanding of each of the team member's contributions to the team.

The example provided by this status report is a template that can be adopted and used by other leaders of teams in higher education settings. Reports such as these serve as effective communication tools and also a method whereby the insights of this article can be successfully integrated. SMART goals, dynamic team member roles, and team life cycle stages can all be recorded and reported in reports such as these.

\section{Summary}

This study shows that an integrated model of team leadership can be used by leaders of higher education institutions (Lara \& Hughey, 2008). Teams of academic administrators can utilize a combination of goal setting, team roles, and team life cycles to work together to help their institutions meet their objectives. Although each of the three primarily elements of this model: goals, roles and stages is important in its own right, a major insight of this article is that these conceptualizations can also be integrated together synergistically to obtain even higher level of team functioning. Thus, by integrating SMART goals with a better understanding of team roles, leaders can keep all team members focused on the SMART goal and not get distracted by the team processes that are 
most salient to their own role. By integrating SMART goals with a better understanding of team life cycle stages, leaders can help teams to formulate SMART goals during early stages, and keep them focused on those goals and not get distracted by team processes. Lastly, integrating a better understanding of team roles with team life cycle stages, leaders can facilitate the dynamics of team roles across life cycles in a way that can optimize team performance.

In addition, throughout this article examples of how this model can be applied to higher education settings were provided. In fact, the model presented here was applied in an actual case in which these concepts were successfully used to lead a group of academic administrators to the successful conclusion of jointly drafting a summary report that describes improvements in student academic and career advising. This example grounds the model presented here in an actual university setting and supports the conclusion that this model is applicable to actual higher educational institution.

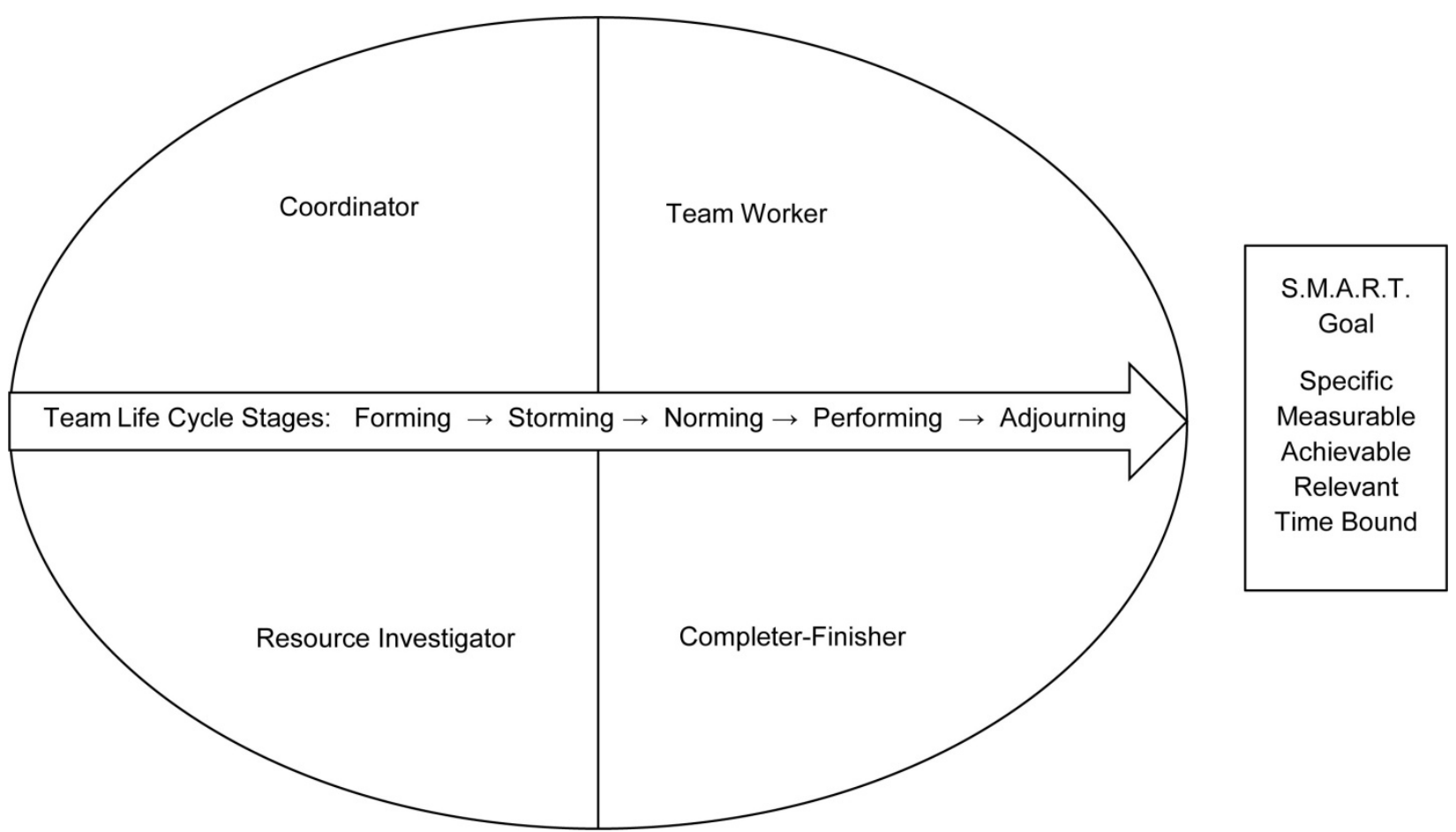

Figure 1. Integrating Goal Setting, Team Roles, and Team Life Cycle Concepts.

Explanation of Figure 1: Examples of team member roles are represented in four parts of the oval, team life cycle stages are represented on the arrow in the center of the oval, and the team goal is represented in the targeted rectangle. 
Date: September 2, 2011

\section{Status Report \\ Report Writing Project Team}

Team Members:

Sandra Garcia, College of Education, Chair Raul Tapia, Undergraduate Studies, Co-Chair Jennifer Maldonado, Academic Advising Center Jack Smith, College of Science Ezekiel Brown, English Department Mary Jones, College of Health Science

Edgar Rau, Department of Electrical and Computer Engineering Richard Van Dyke, College of Education garcia@xyz.edu tapiar@xyz.edu MaldanadoJ@xyz.edu SmithJ@xyz.edu Browne@xyz.edu jones@xyz.edu Rau@xyz.edu Van@xyz.edu

Workgroup Goal: Write a five page report (based on backup documentation) that summarizes the progress toward completion of the 21 student academic and career advising action item in the Quality Enhancement Plan by September 1, 2011.

\section{Current of Workgroup Process Dynamics}

\section{A. Team Stages Current Status}

Forming Storming

Norming
Performing

Adjourning

\section{B. Individual Roles}

Coordinator: Richard Van Dyke

Resource Investigator: Jennifer Maldonado

Team Worker: Raul Tapia

Completer-Finisher(s): Sandra Garcia, Jack Smith

\section{C. $\underline{\text { Action Items }}$}

Since there are few, if any gaps, the most important task is to complete the draft of 5 page summary, which should be done before September 15th 


\section{Workplan Elements, Goals, and Current Status}

A. $\underline{\text { Collect Documentation }}$

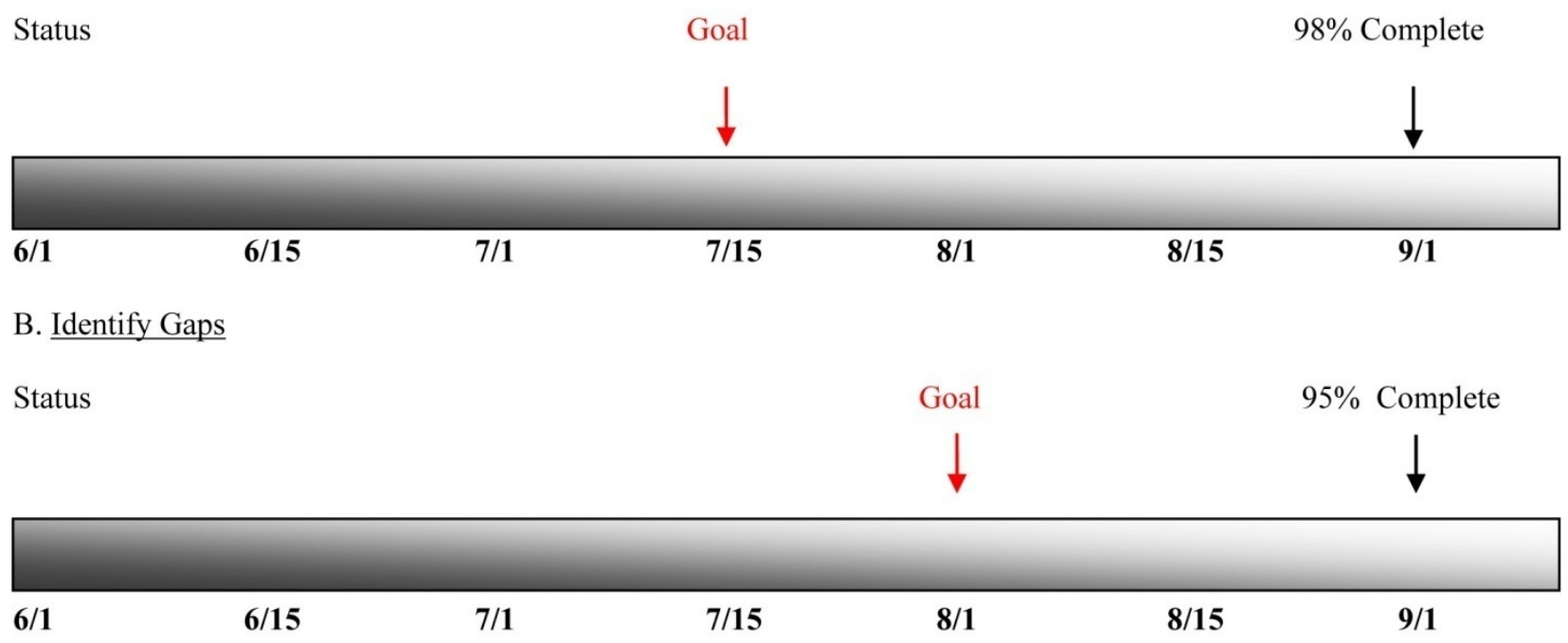

C. Identify Plans to Address Gaps

Status

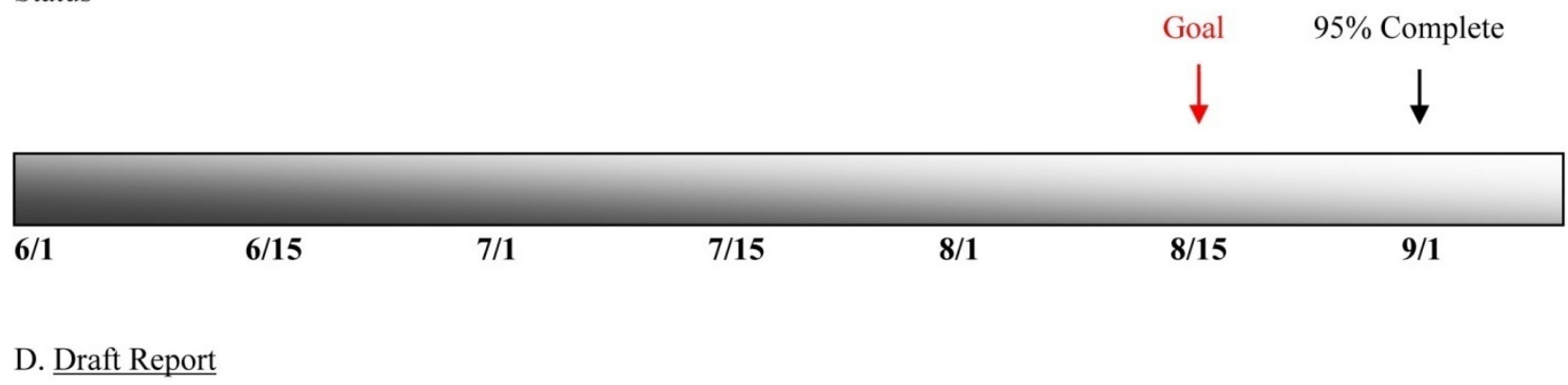

Status

Goal $85 \%$

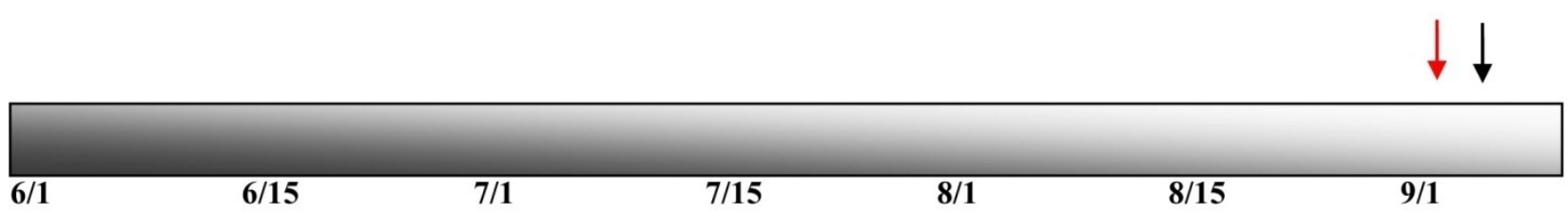

E. Action Items

Finalize 5 page summary of completed items, and identify suggestions for dealing with gaps.

Figure 2. An Example of a Monthly Status Report

\section{References}

Alfieri, J. (2009). Those who dare to lead must seek to serve first: Leadership styles of New Jersey school superintendents. Dissertation Abstracts International, 70(4).

Aloi, S. L. (2005). Best practices in linking assessment and planning. Assessment Update, 17(3), 4-6.

American Society of Higher Education. (2007). Best practices in diversity planning and assessment. $A S H E$ Higher Education Report, 33(1), 89-102.

Aritzeta, A., Swailes, S., \& Senior, B. (2007). Belbin's team role model: Development, validity and applications 
for team building. Journal of Management Studies, 44(1), 96-118. http://dx.doi.org/10.1111/j.1467-6486.2007.00666.x

Barth, T. J. (2004). Teaching PA online: Reflections of a skeptic. International Journal of Public Administration, 27(6), 439-455. http://dx.doi.org/10.1081/PAD-120028819

Belbin, R. M. (1999). Management teams: Why they succeed or fail. Wobur, MA: Butterworth Heinemann.

Bensimon, E. M., \& Neumann, A. (1993). Redesigning collegiate leadership. Baltimore, MD: John Hopkisn University Press.

Browne, E. (2005). Structural and pedagogic change in further and higher education: A case study approach. Journal of Further \& Higher Education, 29(1), 49-60. http://dx.doi.org/10.1080/03098770500037754

Chipunza, C., \& Gwarinda, S. A. (2010). Transformational leadership in merging higher education institutions. South African Journal of Human Resource Management, 8(1), 1-10. http://dx.doi.org/10.4102/sajhrm.v8i1.195

Clawson, J. G. (2006). Level three leadership: Getting below the surface. Upper Saddle River, NJ: Pearson Prentice Hall.

Doran, G. T. (1981). There's a S.M.A.R.T. way to write management's goals and objectives. Management Review, 70(11), 35-36.

Eddy, J. P., \& Murphy, S. D. (1997). 21st Century leadership practices needed for higher education. Education, 117(3), 327-332.

Fincher, M., Katsinas, S., \& Bush, V. B. (2009). Executive management team demography and minority student retention: Does executive team diversity influence the retention of minority students?. Journal of College Student Retention: Research, Theory and Practice, 11(4), 459-481. http://dx.doi.org/10.2190/CS.11.4.b

Gersick, C. (1989). Marking time: Predictable transitions in task groups. Academy of Management Journal, 31 , 9-41. http://dx.doi.org/10.2307/256363

Giles, D., \& Yates, R. (2011). Re-culturing a university department: A case study. Management in Education, 25(3), 87-92. http://dx.doi.org/10.1177/0892020611403805

Gioia, D. A., \& Thomas, J. B. (1996). Identity, image, and issue interpretation: Sensemaking during strategic change in academia. Administrative Science Quarterly, 41(3), 370-403. http://dx.doi.org/10.2307/2393936

Grubb, W. N., \& Flessa, J. J. (2006). “A job too big for one": Multiple principals and other nontraditional approaches to school leadership. Educational Administration Quarterly, 42(4), 518-550. http://dx.doi.org/10.1177/0013161X06290641

Hamdy, H., \& Anderson, M. B. (2006). The Arabian Gulf University College of Medicine and Medical Sciences: A successful model of a multinational medical school. Academic Medicine, 81(12), 1085-1090. http://dx.doi.org/10.1097/01.ACM.0000246680.82786.76

Hirschy, M. J. (2011). Virtual team leadership: A case study in Christian higher education. Christian Higher Education, 10(2), 97-111. http://dx.doi.org/10.1080/15363751003676613

Hornyak, M. J., \& Page, D. (2004). Experiential learning: Introducing faculty and staff to a university leadership development program. Simulation \& $\quad$ Gaming, 35(4), http://dx.doi.org/10.1177/1046878104263974

Keenan, K. M. S., \& Marchel, M. A. (2007). Navigating change in higher education: The partnership experience of department faculty with an organization development consultant. Organization Development Journal, 25(1), 56-69.

Kekale, J. (1999). "Preferred" patterns of academic leadership in different disciplinary (sub)cultures. Higher Education, 37(3), 217-238. http://dx.doi.org/10.1023/A:1003584731452

Kezar, A. J., Carducci, R., \& Contreras-McGavin, M. (2006). Rethinking the “L” Word in Higher Education. Hoboken, N.J.L: Wiley.

Lara, T. M. \& Hughey, A. W. (2008). Implementing the team approach in higher education important questions and advice for administrators. Industry \& Higher Education, 22(4), $245-251$. http://dx.doi.org/10.5367/000000008785201775

Locke, E. A., \& Latham, G. P. (1990). A Theory of Goal Setting \& Task Performance. Englewood Cliffs, NJ: 
Prentice Hall.

Maguad, B. A. (2011). Deming's "profound knowledge": Implications for higher education. Education, 131(4), 768-774.

Mihel, G. (2010). Higher education's future. Journal of Leadership Studies, 4(1), 72-73. http://dx.doi.org/10.1002/jls.20157

Miller, G. P., \& Molina-Ray, C. (2010). Beyond technology dependence. Journal of Leadership Studies, 4(1), 74-77. http://dx.doi.org/10.1002/jls.20156

Patterson, G. (2001). The applicability of institutional goals to the university organisation. Journal of Higher Education Policy \& Management, 23(2), 159-169. http://dx.doi.org/10.1080/13600800120088652

Rowley, J. (1997). Academic leaders: Made or born?. Industrial \& Commercial Training, 29(2), 78-84. http://dx.doi.org/10.1108/00197859710165065

Serrano-Velarde, K. (2010). A fish out of water? Management consultants in academia. Minerva: A Review of Science, Learning \& Policy, 48(2), 125-144. http://dx.doi.org/10.1007/s11024-010-9148-9

Smrekar, C., \& McGraner, K. (2009). From curricular alignment to the culminating project: The Peabody College Ed.D. capstone. Peabody Journal of Education, 84(1), 48-60. http://dx.doi.org/10.1080/01619560802679641

Tuckman, B. (1965). Developmental sequence in small groups. Psychological Bulletin, 63(6), 384-99. http://dx.doi.org/10.1037/h0022100

Tuckman, B., \& Jensen, M. A. C. (1977). Stages of Small-Group Development Revisited. Group \& Organization Management, 2(4), 419-427. http://dx.doi.org/10.1177/105960117700200404

van Ameijde, J. D. J., Nelson, P. C., Billsberry, J., \& van Meurs, N. (2009). Improving leadership in higher education institutions: A distributed perspective. Higher Education, 58(6), 763-779. http://dx.doi.org/10.1007/s10734-009-9224-y

van Dierendonck, D., \& Groen, R. (2011). Belbin revisited: A multitrait-multimethod investigation of a team role instrument. European Journal of Work and Organizational Psychology, 20(3), 345-366. http://dx.doi.org/10.1080/13594321003590580

Wageman, R., Fisher, C. M., Hackman, J. R. (2009). Leading teams when the time is right: Finding the best moments to Act. Organizational Dynamics, 38(3), 192-203. http://dx.doi.org/10.1016/j.orgdyn.2009.04.004

Wageman, R., Nunes, D., Burruss, J., \& Hackman, J. R. (2008). Senior Leadership Teams: What It Takes To Make Them Great. Boston: Harvard Business School Press.

White, K., Carvalho, T., \& Riordan, S. (2011). Gender, power and managerialism in universities. Journal of $\begin{array}{llll}\text { Higher Education Policy \& } & \text { Management, } & 33(2), & \text { 179-188. }\end{array}$ http://dx.doi.org/10.1080/1360080X.2011.559631

Woodfield, S., \& Kennie, T. (2008). "Teamwork" or "Working as a team"? The theory and practice of top team working in UK higher education. Higher Education Quarterly, 62(4), 397-415. http://dx.doi.org/10.1111/j.1468-2273.2008.00399.x 